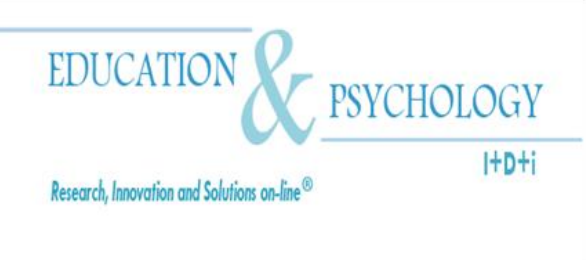

\title{
The Role of Perceived Parental Autonomy Support in Academic Achievement of Asian and Latino American Adolescents
}

\section{Ying Hong Jiang ${ }^{1}$, Jenny Yau ${ }^{1}$, Patricia Bonner ${ }^{1}$, Linda Chiang ${ }^{2}$}

${ }^{1}$ Department of Doctoral Studies in Education, School of Education, Azusa Pacific University, Azusa, California ${ }^{2}$ Department of Foundations and Trans-Disciplinary Studies, School of Education, Azusa Pacific University, Azusa, California

\section{U.S.A.}

Correspondence: Ying Hong Jiang. Doctoral Studies in Education, School of Education, Azusa Pacific University, 701 East Foothill Boulevard, Azusa, CA91702-7000, U.S.A. E-mail: yjiang@apu.edu

(C) Education \& Psychology I+D+i and Editorial EOS (Spain) 


\begin{abstract}
Introduction. Driven by an overarching conceptual framework adapted from SelfDetermination Theory, this study tested the direct and indirect effects of perceived parental academic autonomy support vs. academic planning control on the interrelated variables of adolescents' self-esteem, academic motivation, and academic achievement, using multisample structural equation modeling.
\end{abstract}

Method. A sample of 271 Asian American and 218 Latino American high school students were recruited in Southern California to respond to a questionnaire composed of a battery of adapted and self-constructed scales.

Results. In the Asian American sample, perceived parental academic autonomy support had significant direct positive effects on academic achievement, self-esteem, academic motivation, and indirect effects on academic motivation mediated by self-esteem, while perceived parental academic planning control had direct negative effects on self-esteem and academic achievement. However, in the Latino American sample, perceived parental academic autonomy support had positive indirect effects on academic achievement mediated by academic motivation and self-esteem, and perceived academic planning control had negative direct effects on both self-esteem and academic motivation.

Discussion and Conclusion. Plausible explanations for the different pathways in the two cultural groups were presented from the cultural perspectives. The potentiality of using parental academic autonomy support as a predictor for academic achievement was also discussed.

Keywords: academic self-concept, adolescents, cross-culture, parental acceptance, parental control 


\section{Papel del apoyo parental autónomo percibido, en el rendimiento académico de adolescentes asiáticos y latinoamericanos \\ Resumen}

Introducción. Esta investigación estuvo basada en un un concepto general de una adaptación de la Teoría de la Autodeterminación. Esta investigación evaluó el impacto directo e indirecto en la autoestima de adolecentes del apoyo brindado por sus padres en áreas específica de autonomía académica frente al control de planificación académica de las variables relacionadas entre sí de los adolescentes la autoestima , la motivación académica, y el logro académico. Método. Este trabajo investigativo incluyó una muestra de 271 asiático-americanos y latinos 218 estudiantes estadounidenses de secundaria fueron reclutados en el sur de California para responder a un cuestionario compuesto por una serie de escalas adaptadas y auto-construidas. Se utilizaron múltiples muestras para el modelo de ecuación estructurales.

Resultados. En la muestra asiática, el apoyo de los padres fue percibido en la autonomía académica y tuvo efectos positivos directos sobre el rendimiento académico, la autoestima, la motivación académica, y el efecto indirecto sobre la motivación académica mediada por la autoestima, la percepción de control de los padres. Mientras que los resultados en el área de la planificación académica hubo efectos negativos directos sobre la autoestima y el rendimiento académico. Sin embargo, en la muestra de América Latina, el apoyo de los padres percibido en la autonomía académica tuvo efectos indirectos positivos en el rendimiento académico mediado por la motivación académica y la autoestima, percepción de control y planificación académica tuvo efectos negativos directos en tanto la autoestima y la motivación académica.

Discusiones y Conclusiones. Se presentan explicaciones plausibles para las diferentes vías en los dos grupos culturales desde la perspectiva cultural. Tanbien fue discutido en el papel la potencialidad del uso de la autonomía académica apoyo de los padres como un método para predecir el nivel de rendimiento académico.

Palabras Clave: autoconcepto académico, adolescentes, estudios culturales cruzados, aceptación de los padres, control parental. 


\section{Introduction}

While extensive research has been unpacking the components of social contextual influence on students' academic motivation and achievement, research on Deci and Ryan's (1985) self-determination Theory (SDT) consistently demonstrates that autonomouslymotivated students tend to do well in educational settings, especially with autonomy support from teachers and parents (Lam, Pak \& Ma, 2007; Reeve, 2002). On the basis of SDT and prior literature on parental involvement, the current study examined the role of perceived parental academic autonomy support with interrelated variables in academic achievement among Asian and Latino American high school students, whose cultural backgrounds are commonly considered to be collectivistic oriented (Chao \& Tseng, 2002; Halgunseth, Ispa, \& Rudy, 2006).

\section{Autonomy Support, Self-esteem and Motivation in the Academic Context}

\section{The Need for Autonomy}

Among the three basic psychological needs proposed by SDT: autonomy, competence, relatedness (Ryan \& Deci, 2000a, 2002; Sheldon, Ryan \& Reis, 1996), autonomy is the most extensively examined construct. It is defined as the universal feeling of volition, a sense of choice, and the freedom to take initiative or express opinions (Reis, Sheldon, Gable, Roscoe, \& Ryan, 2000), conceptually and empirically differentiated from individualism or emotional detachment (Chirkov, Ryan, Kim, \& Kaplan, 2003; Kagitchibasi, 2005; Ryan \& Lynch, 1989). Ryan and Deci (2000a) specified that autonomy refers to both acting from inherent interest and integrating values from external influences. Accordingly, when one agrees with the values and follows the advice from external sources, reflective autonomy vs. reactive autonomy (Koestner \& Losier, 1996) is expressed. To feel autonomous, one can be dependent on another person perceived to be supportive and responsive (La Guardia, Ryan, Couchman, \& Deci, 2000) or can willingly conform to endorsed groups values (Ryan, 1993), instead of being externally pressured to comply. Chirkov et al. (2003) confirmed that the influence of autonomy on psychological well-being is not restricted to the individualistic cultures. A recent study by Jang, Reeve, Ryan, and Kim (2009) showed that collectivistically oriented Korean high school students similarly benefited from satisfying experiences of the basic needs in 
the classroom and demonstrated achievement, engagement, intrinsic motivation, and less susceptibility to negative emotional affect. Fulfillment of these psychological needs subsequently enhances students' development of intrinsic motivation, beliefs in their own capacity, and learning strategies to achieve (Pomerantz, Grolnick \& Price, 2005).

\section{Self-determination and the Continuum of Motivation}

SDT (Ryan \& Deci, 2000b) posits that motivation is conceptualized as intrinsic, extrinsic, and amotivation or unwillingness on a continuum, differing in the degree of internalized self-determination and the type of regulatory process (Ryan \& Deci, 2000a; Legault, Green-Demers \& Pelletier, 2006). While intrinsic motivation is the prototype of self-determined behavior (Deci \& Ryan, 1985), generated by interest and pleasure alone, extrinsic motivation, is subjected to varying degrees of external regulation to achieve an instrumental end (Ryan \& Deci, 2000a), and is classified into different types. External regulation is the least autonomous form of extrinsic motivation regulated by the consequences of punishment and rewards. Introjected regulation is subject to quite controlling external regulation, such as self- or others'-approval/disapproval; it only involves partial internalization. Regulation through identification is a more self-determined form of extrinsic motivation, with a high degree of autonomy and personal endorsement of values and behaviors (Chirkov et al., 2003), and integrated regulation is the most autonomous form of extrinsically motivated behavior, fully incorporating the identified values and behaviors into one's life.

Both intrinsic and well integrated extrinsic motivation involve a high degree of selfdetermination, to which satisfaction of the need for autonomy is the main prerequisite (Ryan $\&$ Deci, 2003). High self-determined or autonomous motivation has been associated with better academic performance and stronger academic self-concept (Ahmed \& Bruinsma, 2006; Deci \& Ryan, 1985; Reeve, Bolt \& Cai, 1999). In a cross-cultural study on SDT's model of internalization and regulation of academic values, Asakawa and Csikszentmihalyi (2000) noted greater relative autonomy among Asian Americans than European American students, and the difference was attributed to the more relatedness-supportive Asian cultural background. The SDT model thus suggests a mechanism to explain how academic goals in a culture become self-regulated across generations by means of internalization of values through nurture and support from the social contexts. 


\section{Autonomous vs. Controlled Motivation and Parental Autonomy Support}

In empirical research by Vansteenkiste and colleagues (e.g., Vansteenkiste, Lens, DeWitt, De Witt, \& Deci, 2004; Vansteenkiste, Zhou, Lens, \& Soenens, 2005), intrinsic motivation and integrated extrinsic motivation, located on the "self-determined" end of the continuum and involving more perceived internal control, are usually combined to form an autonomous motivation composite to contrast with controlled motivation composed of introjected and external regulation. Autonomous motivation consistently predicts academic success, positive learning attitudes and reduces psychological maladjustment, whereas controlled motivation function induces opposite results. Furthermore, autonomous motivation is more evident in a social context providing the experience of support for autonomy, competence and relatedness than in a highly controlling setting with the experience of threats of punishment and evaluation or imposed goals (Ryan \& Deci, 2000a, 2002; Vansteenkiste et al., 2005).

Autonomy support represents giving students "moderate structure and guidance" as well as "freedom, volition, and responsibility for themselves" (Legault et al., 2006, p.569). Subsequently, students believe that their ideas are being respected and that they are being granted opportunities to take initiative or to make decisions. In explanation of high school students' lack of academic motivation, Legault et al. (2006) affirm that perceived autonomy support plays a crucial role in determining the extent of internalization, integration of values, type of relative autonomy, and enhancement of self-determined or autonomous motivation. While benefits of teachers' autonomy support on learning motivation have been abundantly documented (e.g., Reeve, 2002), increasing interest in the line of SDT research has been focusing on autonomy support from parents (Soenens \& Vansteenkiste, 2005). It is recognized that parents' "empathic, non-controlling, and encouraging" approach (Soenens et al., 2007, p.643) towards their children promotes volitional or autonomous functioning.

\section{Self-esteem, Self-regulation and Parental Support}

The relationship between parental social support and children's self-esteem has been extensively studied (e.g., Caprara, Scabini \& Regalia, 2006; Levitt, Guacci-Franco \& Levitt, 1993). In defining self-esteem, Rosenberg (1985) focused on children's evaluation of whether their parents think they are important and whether they care what happens to them. On the 
other hand, among all the research attempts to associate academic achievement and selfesteem, Ross and Broh (2000) proposed that it is personal control, not self-esteem, which affects subsequent academic achievement, indicating that personal control increases effort, motivation, and persistence in problem solving, thus improving academic performance. Hence, in the current study, differentiating the constructs, we attempted to capture the mediating effects of both adolescents' perceived self-esteem and self-regulation (self-control as manifested in autonomous motivation) on the relationship between parental autonomy support and academic achievement.

\section{Parental Academic Autonomy Support in Asian and Latino Cultures}

Ryan and Deci (2000a) believe that people from different cultures share the basic psychological needs, which may be, however, expressed or satisfied in different ways. Increasing evidence shows the generalizability of SDT concepts (e.g., basic needs, autonomous motivation, internalization, autonomy support, etc.) among children and adolescents crossculturally (e.g., Chirkov et al., 2003; Hayamizu, 1997; Jang et al., 2009; Yamauchi \& Tanaka, 1998). Recent researchers on cultural orientations argue that even when one orientation is more prevalent than the other in a culture, the psychological needs of autonomy and relatedness (as defined by SDT) can coexist (Jose, Huntsinger, Huntsinger \& Liaw, 2000; Kagitcibasi, 2005). In other words, both close relationship and autonomy (choice and volition) are essential requirements for self-determined goal directed behaviors (Deci \& Ryan, 2000) in individualistic or collectivistic cultures.

Both the Asian and Latino American cultures are generally collectivistic, emphasizing respect for elders, group well-being, and social responsibilities (e.g., Chao \& Tseng, 2002; Harwood, Schoelmerich, Ventura-Cook, Schulze \& Wilson, 1996; Sabogal, Marin, OteroSabogal, VanOss Marin, \& Perez-Stable, 1987). Though Asian and Latino immigrant parents are reported to have higher educational expectations for their children than do native White parents (Pong, Hao \& Gardner, 2005), they are also perceived to have greater control in the parent-child decision-making process than their White counterparts (Kao, 2004). Kao also stated that Asian youth react positively towards increased parental control and discussions about college, whereas Latino youth favor general discussions about school. Generally, students who achieve despite demographic obstacles (such as parents' educational level) usually consider their environment supportive (Rouse, 2001). Despite parents' high expectation for 
school performance and high control in decision-making process, the Asian and Latino adolescents, nonetheless, perceive those controls favorably as obligations (Oyserman, Coon, \& Kemmelmeier, 2002) and guidance. After all, the need for autonomy can be satisfied when one willingly complies with expectations in a trusting relationship.

In the current study, the perceived parental academic autonomy support in the Asian and Latino American families is operationalized as the extent of parent-child discussions regarding school activities or school success, the amount of freedom granted to the adolescents to make decisions and to express their opinions (Kao, 2004), as well as the presence of parents' consistent guidance (Grolnick \& Slowiaczek, 1994). On the other end of the continuum was absence of support, identified as academic planning control in this study, i.e., the lack of opportunity to experience self-expression or decision-making as well as the demand to abide by parents' wishes. Autonomy-supportive parents have children who are more likely to internalize parental norms and be intrinsically motivated (Grolnick \& Ryan, 1989), whereas children of more controlling parents show lower levels of motivation and lower school performance (Grolnick, Deci, \& Ryan, 1997).

\section{The Present Study}

The purpose of this study was to test an integrated model of variables, examining the role of perceived parental academic autonomy support in predicting adolescent academic motivation and achievement via the mediated effect of self-esteem with samples from Asian and Latino American adolescents. It was hypothesized that in both cultures, perceived parental academic autonomy support and academic planning control would have direct as well as indirect effects on autonomous motivation and achievement through the mediated effect of selfesteem.

\section{Method}

Sample and Data Collection Procedure

A total of 580 high school students $(M=250 ; F=326)$ from Southern California in the U.S. participated in the study. The sample consisted of 85 (14.7\%) freshmen, 118 sophomores (20.3\%), 193 (33.3\%) juniors, and 184 (31.7\%) seniors, with 271 (47.8\%) Asian, 218 (38.4\%) 
Latino, and 78 (13.8\%) from other ethnic groups. Sixty-three percent of Asian and 88\% of Latino participants were born in the U.S. The average years of residing in the U.S. were 10.85 and 14.8 for the Asian and Latino immigrant students respectively. Thirty-four percent of Asian and 64\% of Latino participants qualified for free or reduced school lunch. Thirtyseven percent of Asian participants and only $18.1 \%$ of Latino participants' parents had college degrees. A questionnaire composed of a battery of adapted and self-constructed scales was administered to volunteer students with parental written consent in a 30- minute period following a regular class.

\section{Measures and Variables}

Rosenberg Self-Esteem Scale (1965, 1979). Adolescents'self-esteem was assessed by the ten questions on the Rosenberg Self-Esteem Scale $(1965,1979)$ with a converted five-point Likert scale. The values of five negatively worded questions were re-coded before being further analyzed. The exploratory factor analyses revealed two factors composing the five positively worded questions and five negatively worded questions. Both one- factor and two- factor models were further assessed using Confirmatory Factor Analysis with LISREL 8.71 (Joreskog \& Sorborm, 2004). Although the two- factor solution showed better fit for both Asian and Latino samples $(\mathrm{CFI}=.90)$, for this study, we assume the uni-dimensionality of the SelfEsteem Scale (Marsh, 1996; Quilty, Oakman, \& Risko, 2006). The CFI of the one- factor model was both .88 for the Asian and Latino samples modeled separately. The internal consistency reliability of the Self-Esteem Scale indicated by Cronbach's $\alpha$ was .82 for Asian sample and .86 for Latino sample.

High School Academic Motivation Scale (Vallerand, Pelletier, \& Blais, 1992-1993). The 28question scale, based on the Self-Determination Theory (Deci \& Ryan, 1985), was employed to assess students' academic motivation in respect to seven motivation constructs (a) the intrinsic motivation constructs including to know, to experience stimulation, and to accomplish; (b) the extrinsic motivation constructs including identified, introjected, and external regulation, and (c) amotivation. The original 7- point Likert scale was converted to 5- point Likert scale.

Relative Autonomy Index (RAI): We constructed the Relative Autonomy Index (RAI, Grolnick \& Ryan, 1987) as an overall self-determination index measure of the academic motivation 
continuum based on the scores collected using High School Academic Motivation Scale (Vallerand et al., 1992). To compose the RAI, first we assigned a weight to each of the motivation subscales (external regulation, -2; introjected, -1; identified, +1; experience stimulation, +2 ; to know, +2 ; and to accomplish, +2 ) based on their relative position on the continuum of motivation. Then we summed the weighted scores, with the higher RAI scores reflecting a higher degree of self-determined academic motivation. The internal consistency reliability $\alpha$ for the RAI was .85 for Asian sample and .88 for Latino sample.

Perceived Parental Academic Autonomy Support vs. Academic Planning Control Scores: Three questions were constructed to measure parent academic autonomy support: "My parents discuss my course schedule with me"; "My parents research prospective careers and discuss pros and cons with me"; "I research prospective careers and discuss pros and cons with my parents". The other three questions measuring parent academic planning control were "My parents plan my course schedule for me"; "My parents decide extra-curricular activities for me"; "My parents arrange my community service for me regardless of my choice". Participants responded on a 5-point Likert scale ranging from 1 (strongly disagree) to 5 (strongly agree). The Principal Component Analysis (PCA) revealed two factors accounting for $62 \%$ of the variance. Confirmatory Factor Analysis (CFA) using LISREL 8.71 (Joreskog $\&$ Sorborm, 2004) was then conducted to validate the two constructs. Without missing data, the two factor model showed excellent fit with Asian sample, $\chi^{2}(8, N=217)=12.95, p>.05$. The GFI, AGFI, CFI and RMSEA are $.98, .95, .98$, and .05 respectively. The same two factor model also fit fairly well with the Hispanic sample, $\chi^{2}(8, N=178)=22.87, p<.01$. The GFI, AGFI, CFI and RMSEA are .96, .89, .94, and .10 respectively. The internal consistency reliability $\alpha$ for perceived parent academic autonomy support was .72 for Asian sample and .70 for Latino sample, and the reliability $\alpha$ for perceived parent academic planning control is .58 for Asian sample and .68 for Latino sample.

High School Grad Point Average (GPA). Academic achievement was indicated by students' self-reported GPA.

\section{Statistical Analysis}

We first examined the descriptive statistics and the zero order Pearson correlations among the variables. Then, structural equation modeling was employed to test the direct and 
indirect effects of perceived parental academic autonomy support and academic planning control on self-esteem, RAI, and GPA for the two samples.

\section{Results}

Descriptive Statistics

Parental educational level was higher for the Asian sample than for the Latino sample. Latino students had a higher self-esteem level than their Asian counterparts. Interestingly, Asian parents seemed more likely to be academic autonomy supportive as well as academic controlling than Latino parents. While Latino students had higher RAI scores, Asian students had higher GPAs.

Table 1. Means and Standard Deviation of Variables for Asian and Latino Samples

\begin{tabular}{lcccc}
\hline \multicolumn{1}{c}{ Variable /Measure } & $\underline{\mathrm{M}}$ & $\underline{\text { Asian }}$ & \multicolumn{2}{c}{ Latino } \\
& 4.18 & $(1.46)$ & 3.05 & $(1.55)$ \\
\hline Highest Parent Educational Level & 3.49 & $(0.70)$ & 3.88 & $(0.70)$ \\
Self-Esteem & 2.92 & $(0.95)$ & 2.89 & $(0.97)$ \\
$\begin{array}{l}\text { Perceived Parental Academic Autonomy Sup- } \\
\text { port }\end{array}$ & & & & \\
Perceived Parental Academic Planning Control & 2.16 & $(0.83)$ & 1.77 & $(0.74)$ \\
Relative Autonomy Index & 12.42 & $(3.51)$ & 12.83 & $(3.27)$ \\
High School Grade Point Average & 3.47 & $(0.56)$ & 3.24 & $(0.62)$ \\
\hline
\end{tabular}

\section{Correlations}

Zero-order Pearson correlations of key research variables are displayed in Tables 2 and 3, along with Cronbach's internal consistency coefficient alphas for each measure. 
Table 2. Intercorrelations /Coefficient Alphas for Demographic Variables and Measures for Asian Sample

\begin{tabular}{|c|c|c|c|c|c|c|c|c|}
\hline Variable/Measure & 1 & 2 & 3 & 4 & 5 & 6 & 7 & 8 \\
\hline 1. Highest Parent & & & & & & & & \\
\hline Educational Level & & & & & & & & \\
\hline $\begin{array}{l}\text { 2. Years of residing in } \\
\text { the U.S }\end{array}$ & -.04 & - & & & & & & \\
\hline $\begin{array}{l}\text { 3. Qualified for } \\
\text { free/reduced lunch }\end{array}$ & $-.23 * *$ & $-.16^{*}$ & - & & & & & \\
\hline 4. Born U.S. & .01 & $.79 * *$ & $-.15^{*}$ & - & & & & \\
\hline 5. Self Esteem & .10 & .02 & -.04 & .06 & .82 & & & \\
\hline 6. Perceived Parental & & & & & & & & \\
\hline $\begin{array}{l}\text { Academic Autonomy } \\
\text { Support }\end{array}$ & $.24 * *$ & $-.22 * *$ & $-.14 *$ & $-.12 *$ & $.18 * *$ & .72 & & \\
\hline $\begin{array}{l}\text { 7. Perceived Parental } \\
\text { Academic Planning } \\
\text { Control }\end{array}$ & .02 & $-.36^{* *}$ & .04 & $-.22 * *$ & -.11 & $.41 * *$ & .58 & \\
\hline $\begin{array}{l}\text { 8. Relative Autonomy } \\
\text { Index }\end{array}$ & .09 & $-.25 * *$ & -.03 & $-.16^{* *}$ & $.26 * *$ & $.35^{* *}$ & $.13^{*}$ & .85 \\
\hline $\begin{array}{l}\text { 9. High School Grade } \\
\text { Point Average }\end{array}$ & $.15^{*}$ & .00 & .03 & -.05 & $.18 * *$ & $.22 * *$ & -.06 & $.14^{*}$ \\
\hline
\end{tabular}

For the Asian sample, parental education level positively correlated with academic autonomy support and GPA. Length residing in the U.S. negatively correlated with parental academic autonomy support, along with academic planning control and RAI. Qualification for free/reduced lunch status negatively correlated with parental academic autonomy support. Being born in the U.S. negatively correlated with both parental academic autonomy support and parental academic planning control and RAI. Parental academic autonomy support positively correlated with parental academic planning control, RAI, and GPA. RAI and GPA positively correlated with each other. See the Table 3. 
Table 3. Intercorrelations /Coefficient Alphas for Demographic Variables and Measures for Latino Sample

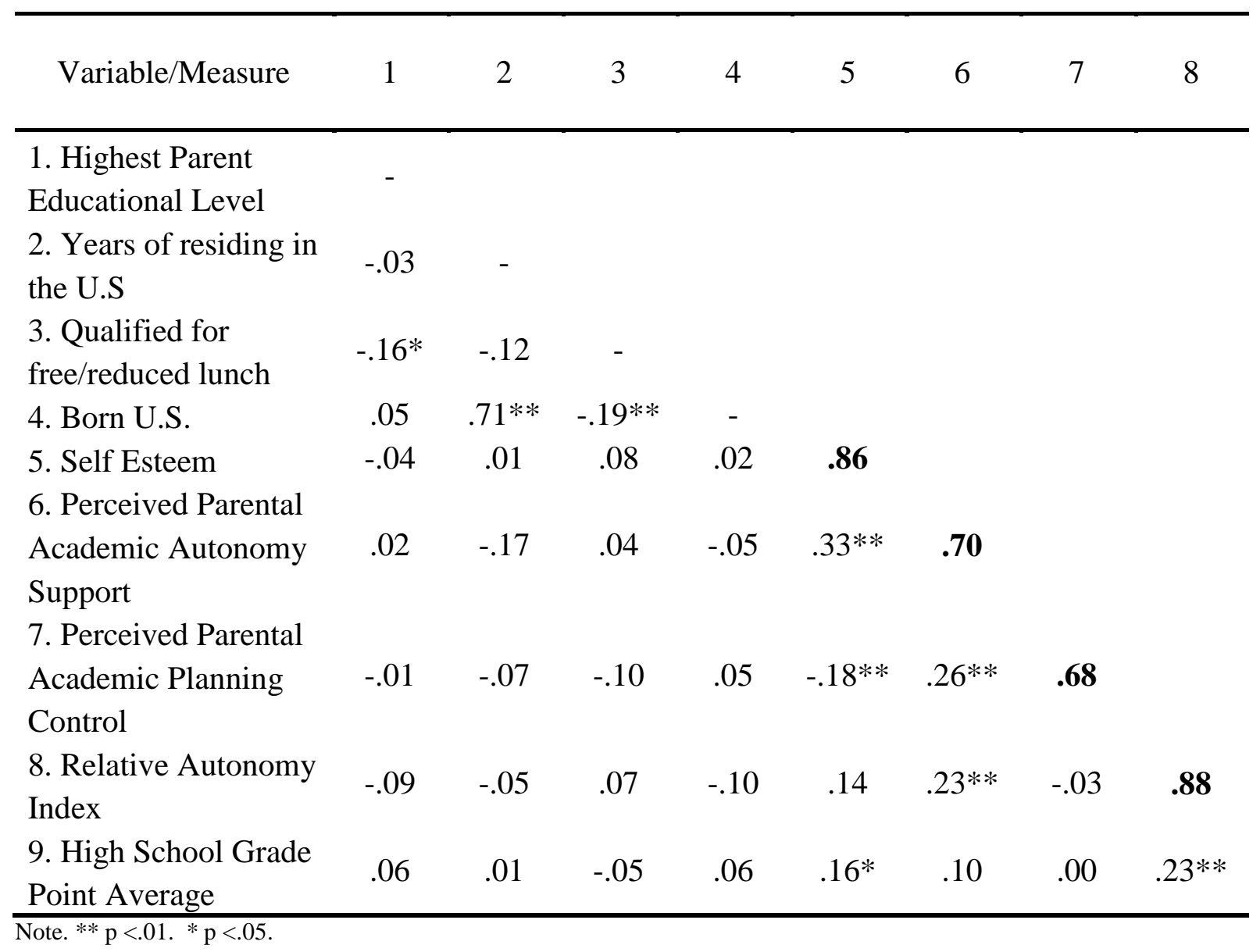

The pattern of correlations for the Latino sample was somewhat different. None of the demographic variables significantly correlated with the key research variables. Self-esteem positively correlated with parental academic autonomy support and GPA, and negatively correlated with parental academic planning control. Parental academic autonomy support positively correlated with parental academic planning control, and RAI. Similar to the Asian sample, RAI and GPA correlated with each other.

\section{Structural Equation Modeling}

The current study hypothesized that perceived academic autonomy support and academic planning control, the two related yet distinct constructs have direct effects on academic achievement. It was also hypothesized that these two constructs had indirect effects on aca- 
demic achievement through self-esteem and academic motivation indicated by the Relative Autonomy Index (RAI).

Combined and multi-sample structural models. Structural models of relationships among perceived parental academic autonomy support and academic planning control, self-esteem, RAI, and academic achievement were tested using LISREL 8.71 (Jo“reskog \& So“rbom, 2004) with the combined Asian and Latino samples $(\mathrm{N}=489)$. The path coefficients were obtained through standardized solutions.

Figure 1 is the path diagram describing the pathways of significant effects on academic achievement via self-esteem and the RAI. The goodness of fit statistics indexes are displayed in Table 4 . The hypothesized models seemed to reasonably fit the covariance matrix observed in the combined samples.

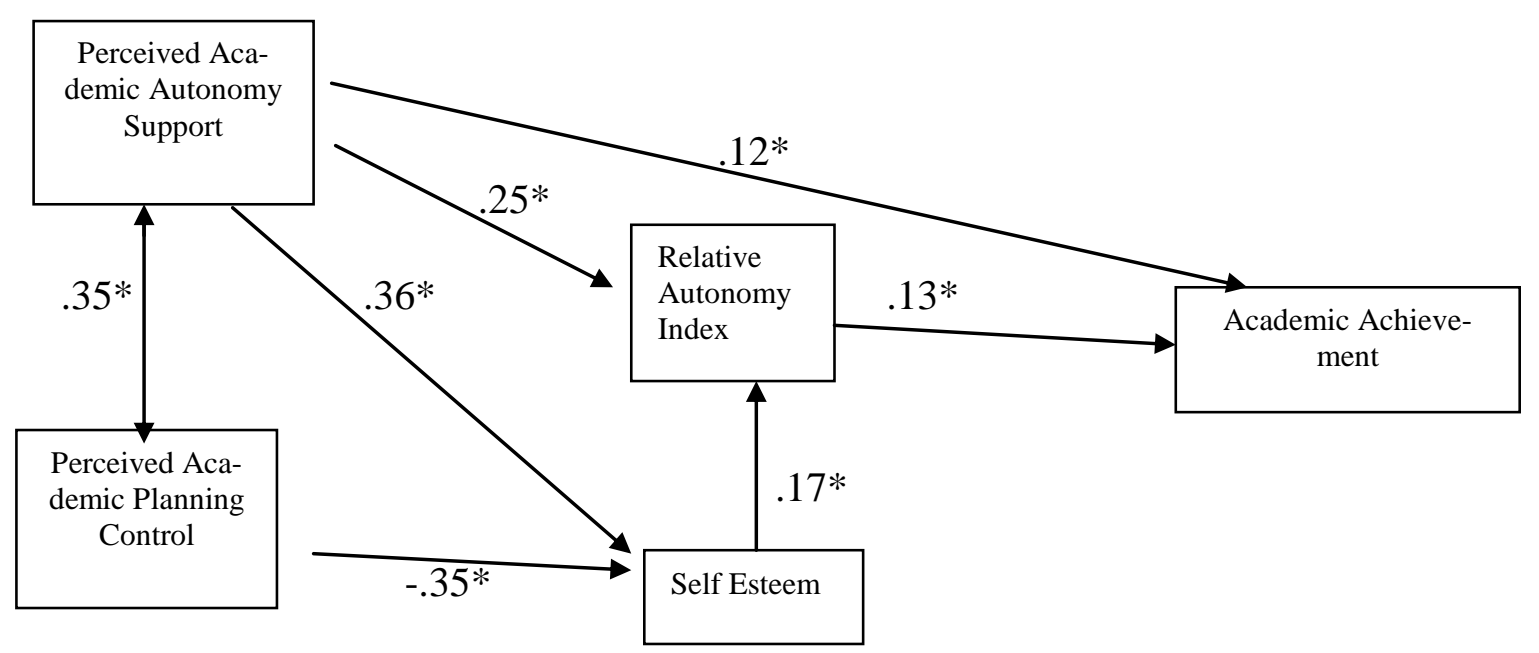

Figure 1. Testing significant effects on academic achievement in via RAI in combined Asian and Latino samples

Multi-sample structural models were then performed based on the significant paths shown in Figure 3 and Figure 4 to test the invariance between Asian and Latino samples based on the four hypotheses formulated. Hypothesis A postulates the invariance between the two co-variance matrices, $\mathrm{H}_{\Sigma}: \boldsymbol{\Sigma}^{(1)}=\boldsymbol{\Sigma}^{(2)}$. Hypothesis B postulates the invariance of the relationship between exogenous and endogenous variables, $\mathrm{H}_{\Gamma}: \Gamma^{(1)}=\Gamma^{(2)}$. Hypothesis C postulates the invariance of the relationship between the endogenous variables, $\mathrm{H}_{\beta}$ : $\boldsymbol{\beta}^{(1)}=\boldsymbol{\beta}^{(2)}$. The last hypothesis D postulates that invariance for the relationship between all the exogenous and 
the endogenous variables, $\mathrm{H}_{\Gamma}: \Gamma^{(1)}=\Gamma^{(2)}$, and $\mathrm{H}_{\beta}: \boldsymbol{\beta}^{(1)}=\boldsymbol{\beta}^{(2)}$. The fit statistics for testing the hypotheses are also displayed in Table 4.

Table 4. Goodness-of-Fit Indicators of Models Containing Only Significant Effects for Combined Asian and Latino Samples and the Global Goodness of Fit Indicators for the Multi-Sample Models

\begin{tabular}{cccccccc}
\hline Model & df & $\chi^{2}$ & $\chi^{2} / \mathrm{df}$ & GFI & AGFI & CFI & $\begin{array}{c}\text { RMSE } \\
\text { A }\end{array}$ \\
\hline Model in Figure 1 & \multicolumn{7}{c}{ Combined Sample $(\mathrm{N}=469)$} \\
4 & 1.95 & 0.49 & 1.00 & 0.99 & $1 / 00$ & 0.00 \\
\hline
\end{tabular}

Multi-Sample Global Goodness of Fit Indicators (Asian N=271, Latino N=218) Model in Fig 1

\begin{tabular}{|c|c|c|c|c|c|c|c|}
\hline Hypothesis $\mathrm{A} \mathrm{H}_{\Sigma}: \Sigma^{(1)}=\Sigma^{(2)}$ & 8 & $17.93 *$ & 2.24 & N/A & N/A & 0.95 & 0.072 \\
\hline Hypothesis B $\mathrm{H}_{\Gamma}: \Gamma^{(1)}=\Gamma^{(2}$ & 12 & $22.44 *$ & 1.87 & N/A & N/A & 0.95 & 0.06 \\
\hline $\begin{array}{c}\text { Hypothesis } \mathrm{C} \mathrm{H}_{\beta}: \beta^{(1)}=\beta^{(2)} \\
\text { Hypothesis } \mathrm{D}\end{array}$ & 10 & $23.41 *$ & 2.34 & N/A & N/A & 0.93 & 0.074 \\
\hline$: \Gamma^{(1)}=\Gamma^{(2)}$, and $H_{\beta}: \beta^{(1)}=\beta^{(2)}$ & 14 & $28.22 *$ & 2.05 & N/A & N/A & 0.92 & 0.065 \\
\hline
\end{tabular}

Note. GFI= goodness-of-fit; AGFI = adjusted goodness-of-fit; CFI = comparative fit; RMSEA=root-mean-square error approximation; $* \mathrm{p}<.05$.

The hypotheses of invariance between the Asian and Latino samples were all rejected for the model in delineated in Figure 1, suggesting the two samples vary in the relationships among the variables being investigated. Thus, separately modeling the structural relationships for the Asian and Latino samples seemed to be a reasonable choice

Separate sample structural models. Structural models of relationships among perceived parental academic autonomy support and academic planning control, self-esteem, RAI, and academic achievement were tested using LISREL 8.71 (Jo“reskog \& So“rbom, 2004) with Asian and Latino samples separately. The path coefficients were obtained through standardized solutions. Figures 2 and 3 are the path diagrams describing the pathways of significant effects on academic achievement via self-esteem and the RAI. Table 5 displays the goodness of fit statistics for these models. The hypothesized models seemed to reasonably fit the covariance matrix observed in the two samples. 
Table 5. Goodness-of-Fit Indicators of Models Containing Only Significant Effects for Asian and Latino Samples

\begin{tabular}{|c|c|c|c|c|c|c|c|}
\hline Model & df & $\chi^{2}$ & $\chi^{2} / \mathrm{df}$ & GFI & AGFI & CFI & RMSEA \\
\hline \multicolumn{8}{|c|}{ Asian $(\mathrm{N}=271)$} \\
\hline Model in Fig 2 & 4 & 2.77 & 0.69 & 1.00 & 0.98 & 1.00 & 0.00 \\
\hline \multicolumn{8}{|c|}{ Latino $(\mathrm{N}=218)$} \\
\hline Model in Fig 3 & 4 & 0.17 & 0.04 & 1.00 & 1.00 & 1.00 & 0.00 \\
\hline
\end{tabular}

Note. GFI= goodness-of-fit; AGFI = adjusted goodness-of-fit; CFI = comparative fit; RMSEA=root-mean-square error approximation.

Based on the results shown in Figures 2, in the Asian sample, perceived parental academic autonomy support and academic planning control were correlated. Perceived parental academic autonomy support had significant positive direct effects on self-esteem, RAI, and academic achievement as well as indirect effects on RAI via self-esteem. Perceived parental academic planning control had a negative direct effect on self esteem and academic achievement as well as indirect effect on RAI via self esteem. Self-esteem had a positive direct effect on RAI. Nevertheless, RAI did not significantly influence academic achievement.

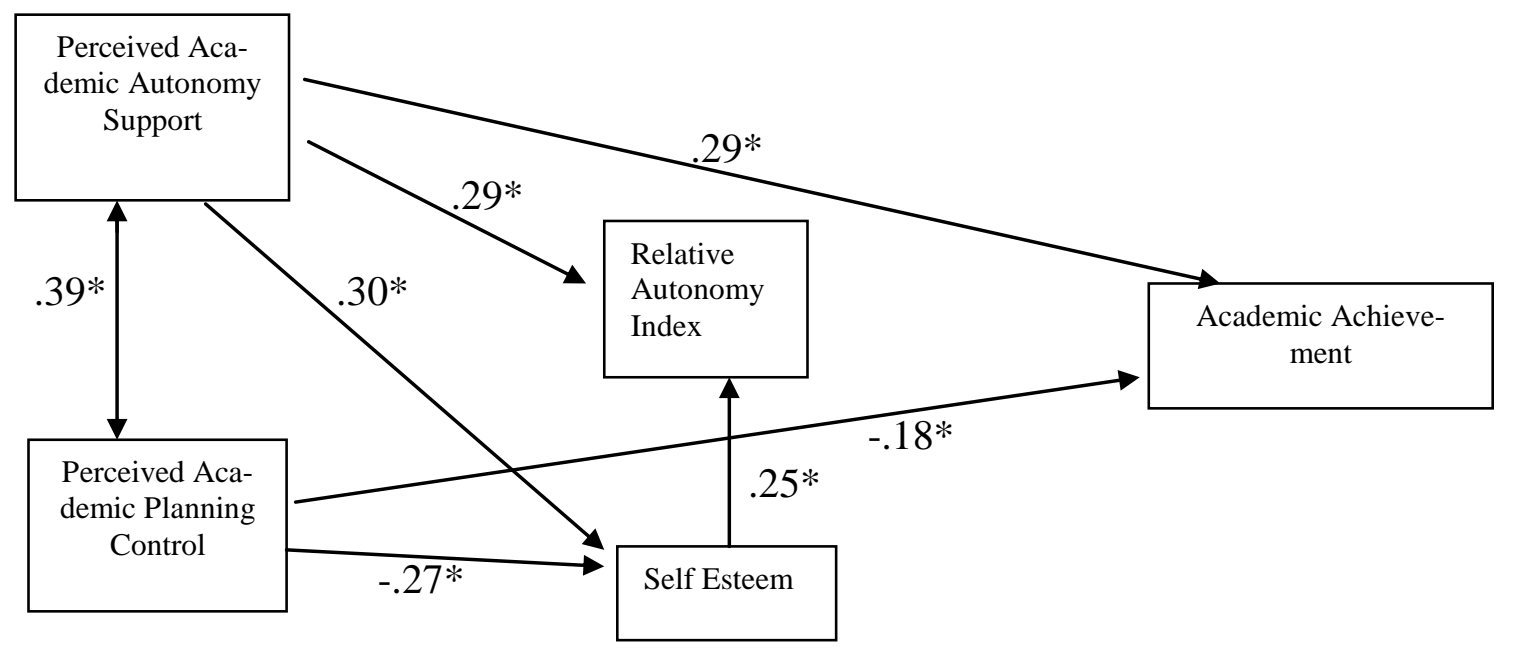

Figure 2. Testing significant effects on academic achievements in via RAI in Asian sample 


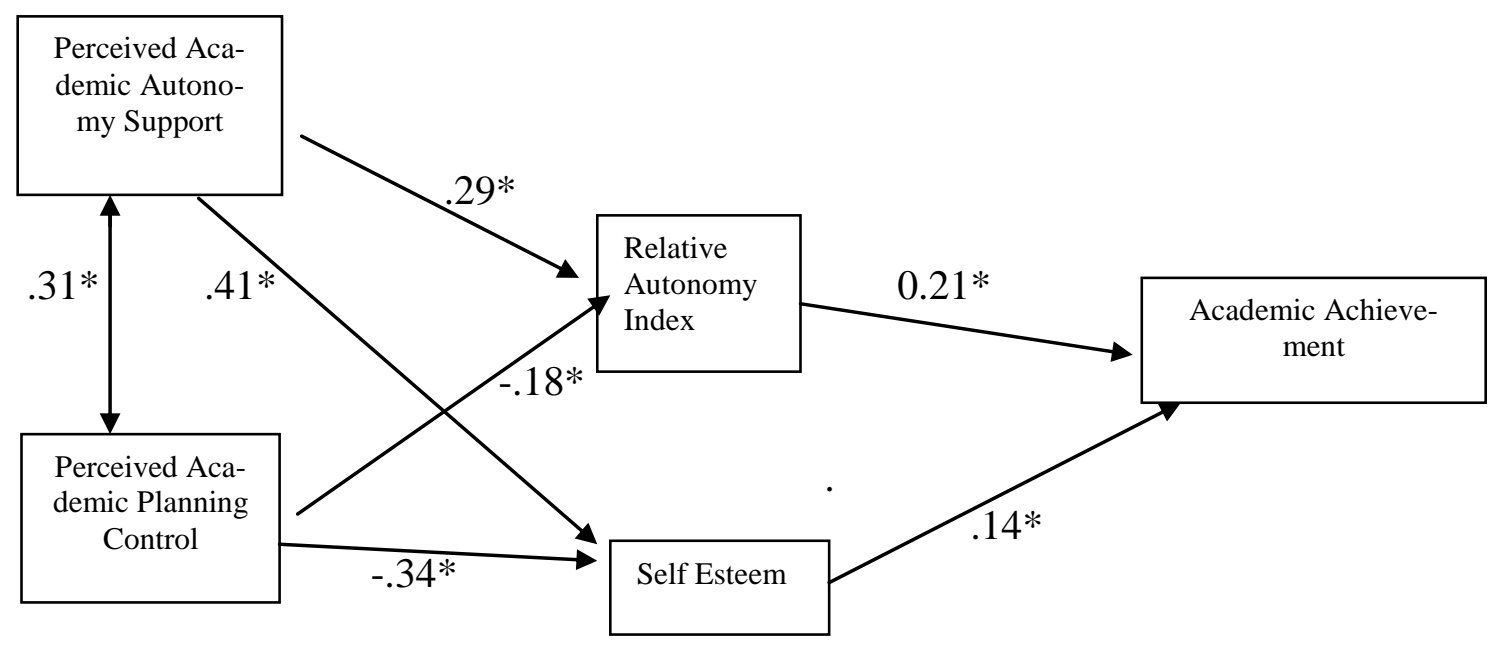

Figure 3. Testing significant effects on academic achievement via RAI in Latino sample

Figure 3 shows that in the Latino sample, perceived academic autonomy support had significant positive direct effects on RAI and self-esteem and indirect effects on academic achievement via RAI and self-esteem. Perceived academic planning control had significant negative direct effects on RAI and self-esteem and indirect effects on achievement via RAI and self-esteem. Both RAI and self- esteem had positive effects on academic achievement. For both groups, parental autonomy support was strongly, positively associated with the adolescents' self-esteem and RAI (indicating self-control and self-determination in achievement motivation), which subsequently predicted academic achievement for Latino sample but not significantly for Asian sample.

\section{Discussion}

Results from the structural models among the Asian American adolescents supported the hypothesis regarding the direct effects of perceived parental academic autonomy support and academic planning control on academic achievement; however, indirect effects on academic achievement through self-esteem, relative autonomy index, or academic motivation were not shown. Conversely, results among the Latino American adolescents were consistent with our hypothesis about the indirect effects of perceived parental academic autonomy support and academic planning control on academic achievement, mediated by its direct effect on self-esteem, and the relative autonomy index; yet, direct effects were not demonstrated. Overall, the structural equation modeling analyses provided empirical evidence for the positive 
effects of perceived parental academic autonomy support on self-esteem, academic motivation and achievement in both cultures. Parents' academic planning control, on the other hand, showed negative effects on self-esteem in both samples. Plausible explanations for the different pathways in the two cultural groups are presented below. The potentiality of using parental academic autonomy support as a predictor for academic achievement is also discussed.

\section{Impact of Cultural Values on the Effect of Parental Academic Autonomy Support}

The difference in the pathways in the tested models for the two cultures may reflect variation in the salient factors associated with academic achievement. Apparently, Asian American adolescents tend to strive for academic achievement in the presence of perceived parental academic autonomy support alone (direct effect), but Latino American youth need additional buttress from self-esteem as well as autonomous motivation (as indicated by RAI) induced by their perceived parental autonomy support (indirect effects). Self-esteem and autonomous motivation seem to play a more significant mediating role among the Latino American adolescents than their Asian counterparts. As reviewed by Pomerantz et al. (2005), when children's psychological needs are satisfied, they may develop a positive approach to achievement along three different “dimensions", namely, autonomous motivation, children's beliefs in their own capacity for achievement, and learning strategies (p. 260). Subsequently, the absence of the indirect effect of parental academic autonomy support on achievement through its effects on self-esteem or autonomous motivation in the Asian American sample may actually indicate that these adolescents had possibly approached achievement through other dimensions which were not measured in our study. As a matter of fact, development of effective learning strategies has been identified as one of the learning approaches of achievement-oriented Chinese adolescents (Li, 2002).

Another possible explanation is that the mediating effect of these variables is undermined in the Asian culture by its strong socialization of academic aspiration. The cultural value of academic achievement is so strongly endorsed that parents' academic values, expectations, and practice on advancing academic skills have been internalized by children readily at an early age, even before entering school (Sy \& Schulenberg, 2005). Instead of being perceived as pressure to perform, adolescents autonomously assume the pursuit of academic success as their own goal. Steinberg et al. (1992) stated that self-esteem may not be highly valued in the Chinese culture. A more pertinent interpretation could be that the self-esteem of Chine- 
se students is so dominantly built upon academic success that self-worth from other life aspects may appear insignificant in comparison. Additionally, the Asian American sample may illustrate what Ross and Broh (2000) have explained, i.e., it is personal control, rather than self-esteem, which actually affects autonomous motivation and subsequently academic achievement. Measurement of the academic self-esteem instead of an overall self-esteem should be able to reveal the mediating effect of this factor more accurately. Findings about the Asian sub-sample in the study Ahmed and Bruinsma (2006) specifically illustrate that academic self-concept, but not the overall self-esteem, is directly related to autonomous motivation as well as academic achievement.

Furthermore, the cultural values of these groups may account for the variation in the mediating factors. In comparing Chinese and Mexican American adolescents, Hardway and Fuligni (2006) found that although adolescents from both cultures emphasized family obligations and assistance to family, adolescents from Mexican families spent more time assisting their families on a daily basis and Chinese adolescents spent more time on studying. Besides, Latino parents rated children's socio-emotional characteristics as more important than academic aspects of school achievement than did Asian American or European-American parents (Okagaki \& Frensch, 1998) - - a cultural characteristic of placing greater value on social character rather than an individual's possession of knowledge or expertise (Greenfield et al., 2006). Cultural values for academic achievement can guide one's approach to academic achievement. Hence, among the Latino American youth, or in cultures which do not highly emphasize academic excellence in competition, high self-esteem (i.e., good overall selfevaluation) or autonomous motivation functions as a necessary dynamic for academic accomplishment For instance, recent research has been suggesting that a sense of belonging is crucial to motivate Latino American students' engagement in academic activities (Faircloth \& Hamm, 2005; Herman \& Tucker, 2000), strongly endorsing the significance of self-worth and social support. Autonomous motivation develops when the youth find meaning in academic excellence and as a result, produce strong academic performance.

\section{Parental Autonomy Support as a Predictor of Parental Influence}

Inherently, parental autonomy support is a more pertinent and comprehensive parent variable to predict students' academic achievement than a general concept of parental involvement. Nevertheless, this study only measured adolescents' perception of the extent of free- 
dom granted for participation in the decision-making process regarding their academic activities or choices. When studying the autonomy supportive teachers, Reeve (2002) has indicated characteristics such as spending time listening, praising the quality of performance, flexibility, and motivating through interest. The construct of parental autonomy support can be further explored with considerations of cultural differences in expectations and expressions of autonomy support.

Legault et al. (2006) expressed that while teachers exerted their academic impact mostly through competence, parents and friends displayed their influence most strongly through relatedness. In the Asian and Hispanic cultures which delineate family connectedness in terms of fulfilling obligations and expectations, autonomy and relatedness can be conceptualized as complementary needs. On one hand, sharing decision-making power and talking about school choices with parents cultivate connectedness (Marchant, Paulson \& Rothlisber, 2001) and competence in students (Grolnick \& Slowiaczek, 1994), which are subsequently associated with students' academic motivation and achievement. On the other hand, students perceive parents' autonomy support through parents' willingness to aspire, offer, or sacrifice for the children's education and would not consider parents' imperative style of communication "cold and distant" (Greenfield et al., 2006). Although it is beyond the measures in this study to explain this intriguing mechanism, at least some light has been shed on understanding why the perceived parental academic autonomy support and perceived parental academic control scores were positively correlated in our samples. Future studies need to examine the interrelated influence of autonomy and relatedness in non-western cultural communities.

\section{Limitations and Future Research}

As indicated above, future studies should aim for a more comprehensive operational definition and measurement of parental autonomy support. Besides, as recent researchers have paid attention to the distinct influences from father and mother to boys and girls, separate measurements of parental autonomy support with fathers and mothers are recommended. Another limitation of this study is the lack of account of any possible interactional effect of child characteristics and parental practices (Pomerantz et al., 2005). For instance, lowachieving children may benefit more from parental autonomy support than high-achieving ones in terms of the improvement in performance ( $\mathrm{Ng}$, Kenny-Benson \& Pomerantz, 2004). 
In sum, future research on the role of parental autonomy support can include varied measurements (besides self-reports) and students of varied achieving levels among different cultures.

\section{Conclusion}

The current study has essentially substantiated the generalizability of SDT-based research in Asian and Latino American ethnic cultures. Based on prior tested models, we have included the construct of perceived parental autonomy support in the models and confirmed its positive effect on self-esteem, academic motivation, and academic achievement. The integrated models provide evidence of cultural differences in the mediating effects of self-esteem and autonomous motivation in the relationship between perceived parental academic autonomy and academic achievement. Findings of this study should be beneficial to home-school collaboration efforts.

\section{References}

Ahmed, W., \& Bruinsma, M. (2006). A structural model of self-concept, autonomous motivation and academic performance in cross-cultural perspective. Electronic Journal of Research in Educational Psychology, 10(4-3), 551-576.

Asakawa, K., \& Csikszentmihalyi, M. (2000). Feelings of connectedness and internalization of values in Asian American adolescents. Journal of Youth and Adolescence, 29, 121145.

Caprara, G. V., Scabini, E., \& Regalia, C. (2006). The impact of perceived family efficacy beliefs on adolescent development. In F. Pajares \& T. Urdan (Eds.), Self-efficacy beliefs of adolescents (pp. 97-116). Greenwich, CT: Information Age Publishing.

Chao, R., \& Tseng, V. (2002). Parenting of Asians. In M. Bornstein (Ed.), Handbook of parenting: Vol. 4: Social conditions and applied parenting, 2nd edition (pp. 59-93). Mahwah, NJ: Erlbaum.

Chirkvov, V., Ryan, R. M., Kim, Y., \& Kaplan, U. (2003). Differentiating autonomy from individualism and independence: A self-determination theory perspective on internalization of cultural orientations and well-being. Journal of Personality and Social Psychology, 84(1), 97-110.

Deci, E. L., \& Ryan, R. M. (1985). Intrinsic motivation and self-determination in human behavior. New York: Plenum Press. 
Deci, E. L., \& Ryan, R. M. (2000). The "What" and "Why" of goal pursuits: Human needs and the self-determination of behavior. Psychological Inquiry, 11(4), 227-268.

Faircloth, B. S., \& Hamm, J. V. (2005). Sense of belonging among high school students representing 4 ethnic groups. Journal of Youth and Adolescence, 34(4), 293-309.

Fuhrman, T., \& Holmbeck, G. (1995). A contextual-moderator analysis of emotional autonomy and adjustment in adolescence. Child Development, 66, 793-811.

Greenfield, P. M., Trumbull, E., Keller, H., Rothstein-Fisch, C., Suzuki, L., \& Quiroz, B. (2006). Cultural conceptions of learning and development. In P.A. Alexander (Ed.), Handbook of Educational Psychology (pp. 675-692), Mahwah, NJ: Erlbaum.

Grolnick, W. S., \& Ryan, R. M. (1987). Autonomy in children's learning: An experimental and individual difference investigation. Journal of Personality and Social Psychology, $52,890-898$.

Grolnick, W. S., \& Ryan, R. M. (1989). Parent styles associated with children's selfregulation and competence in school. Journal of Educational Psychology, 81, 143154.

Grolnick, W. S., Deci, E. L \& Ryan, R. M. (1997). Internalization with the family: The self-determination theory perspective. In J. E. Grusec \& L. Kuczynski (Eds.), Parenting and children's internalization of values (pp.135-161). New York: Wiley.

Grolnick, W. S., \& Slowiaczek, M. L. (1994). Parents' involvement in children's schooling: A multidimensional conceptualization and motivational model. Child Development, 65, 237-252.

Halgunseth, L. C., Ispa, J. M., \& Rudy, D. (2006). Parental control in Latino families: An integrated review of the literature. Child Development, 77, 1268-1281.

Hardway, C., \& Fuligni, A. (2006). Dimensions of family connectedness among adolescents with Mexican, Chinese, and European backgrounds. Developmental Psychology, 42, 1246-1258.

Harwood, R., Schoelmerich, A., Ventura-Cook, E., Schulze, P., \& Wilson, S. (1996). Culture and class influences on Anglo and Puerto Rican mothers' beliefs regarding long-term socialization goals and child behavior. Child Development, 67, 2446-2461.

Hayamizu, T. (1997). Between intrinsic and extrinsic motivation: Examination of reasons for academic study based on the theory of internalization. Japanese Psychological Research, 37, 98-108. 
Herman, K. C., \& Tucker, C. M. (2000). Engagement in learning and academic success among at-risk Latino American students. Journal of Research and Development in Education, 33(3), 129-136.

Jang, H., Reeve, J., Ryan, R., \& Kim, A. (2009). Can self-determination theory explain what underlies the productive, satisfying learning experiences of collectivistically oriented Korean students? Journal of Educational Psychology, 101(3), 644-661.

Jöreskog, K. G., \& Sörbom, D. (2004). LISREL 8.71 for Windows [Computer Software].

Lincolnwood, IL: Scientific Software International.

Jose, P., Huntsinger, C., Huntsinger, P., \& Liaw, F. (2000). Parental values and practices relevant to young children's social development in Taiwan and the United States. Journal of Cross-Cultural Psychology, 31, 677-702.

Kagitcibasi, C. (2005). Autonomy and relatedness in cultural context: Implications for self and family. Journal of Cross-Cultural Psychology, 36(4), 403-422.

Kao, G. (2004). Parental influences on the educational outcomes of immigrant youth. The International Migration Review, 38(2), 427-449.

Koestner, R. \& Losier, G. (1996). Distinguishing reactive versus reflective autonomy. Journal of Personality, 64, 465-494.

La Guardia, J., Ryan, R., Couchman, C., \& Deci, E. (2000). Within-person variations in attachment style and their relations to psychological need satisfaction. Journal of Personality and Social Psychology, 79, 367-384.

Lam, S., Pak, T. S., \& Ma, W. Y. K. (2007). Motivating instructional contexts. In P. R. Zelick (Ed.), Issues in the psychology of motivation (pp.115-132). Nova Science Publishers, Inc.

Legault, L., Green-Demers, I., \& Pelletier, L. (2006). Why do high school students lack motivation in the classroom? Toward an understanding of academic amotivation and the role of social support. Journal of Educational Psychology, 98(3), 567-582.

Levitt, M. J., Guacci-Franco, N., \& Levitt, J. L. (1993). Convoys of social support in childhood and early adolescence: Structure and function. Development Psychology, 29, 811-818.

Li, J. (2002). Learning models in different cultures. In J. Bempechat \& J.G. Elliott (Eds.), Learning in culture and context: Approaching the complexities of achievement motivation in student learning (pp.45-63), New directions for child and adolescent development. San Francisco. CA: Jossey-Bass. 
Marchant, G. J., Paulson, S. E., \& Rothlisberg, B.A. (2001). Relations of middle school students' perceptions of family and school contexts with academic achievement. Psychology of Schools, 38(6), 505-519.

Marsh, H. W. (1996). Positive and negative Global Self-Esteem: A substantively meaningful distinction or artifactors? Journal of Personality and Social Psychology, 70(4), 810819.

Ng, F. F., Kenny-Benson, G. A., \& Pomerantz, E. M. (2004). Children's achievement moderates the effects of mothers' use of control and autonomy support. Child Development, 75, 764-780.

Okagaki, L., \& Frensch, P. (1998). Parenting and children's school achievement: A multiethnic perspective. American Educational Research Journal, 35, 123-144.

Oyserman, D., Coon, H., \& Kemmelmeier, M. (2002). Rethinking individualism and collectivism: Evaluation of theoretical assumptions and meta-analyses. Psychological Bulletin, $128,3-72$.

Pomerantz, E. M., Grolnic, W. S., \& Price, C. E. (2005). The role of parents in how children approach achievement. In A. J. Elliot \& C. S. Dweck (Eds.), Handbook of competence and motivation (pp. 259-277). NY: The Guildford Press.

Pong, S., Hao, L., \& Gardner, E. (2005). The role of parenting styles and social capital in the school performance of immigrant Asian and Hispanic adolescents. Social Science Quarterly, 86(4), 928-950.

Quity, L. C., Oakman, J. M., \& Risko, E. (2006). Correlates of the Rosenberg Self-Esteem Scale methods effects. Structural Equation Modeling, 13(1), 99-117.

Reeve, J., Bolt, E., \& Cai, Y. (1999). Autonomy-supportive teachers: How they teach and motivate students. Journal of Educational Psychology, 91, 537-548.

Reeve, J. (2002). Self-determination theory applied to educational settings. In E. L. Deci \& R.M Ryan (Eds.), Handbook of self-determination research (pp. 183-203). Rochester, NY: University of Rochester Press.

Reis, H., Sheldon, K. Gable, S., Roscoe, J., \& Ryan R. (2000). Daily well being: The role of autonomy, competence, and relatedness. Personality and Social Psychology Bulletin, $26,419-435$.

Rosenberg, M. (1965). Society and the adolescent self-image. Princeton, NJ: Princeton University Press.

Rosenberg, M. (1979). Conceiving the Self. New York: Basic Books. 
Rosenberg, M. (1985). Self-concept and psychological well-being in adolescence. In R. Leahy (Ed.), The development of self (pp. 205-246). New York: Academic Press.

Ross, C. E. \& Broh, B. A. (2000). The roles of self-esteem and the sense of personal control in the academic achievement process. Sociology of Education, 73, 270-284.

Rouse, K. A. (2001). Resilient students' goals and motivation. Journal of Adolescence, 24, 461- 472 .

Ryan, R. (1993). Agency and organization: Intrinsic motivation, autonomy, and the self in psychological development. In J. E. Jacobs (Vol. Ed.) \& R. Dienstbier (Series Ed.), Nebraska Symposium on Motivation: Vol. 40. Developmental perspectives on motivation (pp. 1-56). Lincoln: University of Nebraska Press.

Ryan, R. M., \& Deci, E. L. (2000a). Self-determination theory and the facilitation of intrinsic motivation, social development, and well-being, American Psychologist, $55(1), 68-78$.

Ryan, R. M., \& Deci, E. L. (2000b). Intrinsic and extrinsic motivations: Classic definitions and new directions. Contemporary Educational Psychology, 25, 54-67.

Ryan, R. M. \& Deci, E. L., (2002). Overview of self-determination theory: An organismic dialectical perspective. In E. L. Deci \& R.M. Ryan (Eds.), Handbook of selfdetermination research (pp. 3-33). Rochester, NY: University of Rochester Press.

Ryan, R. M., \& Deci, E. L. (2003). On assimilating identities to the self: A SDT perspective on internalization and integration within cultures. In M.R. Leary \& J. P. Tangney (Eds.), Handbook of self and identity (pp. 253-274). New York: Guilford Press.

Ryan, R., \& Lynch, J. (1989). Emotional autonomy versus detachment: Revisiting the vicissitudes of adolescence and young adulthood. Child Development, 60, 340-356.

Sabogal, F., Marin, G., Otero-Sabogal, R., VanOss Marin, B., \& Perez-Stable, E. (1987). Hispanic familism and acculturation: What changes and what doesn't? Hispanic Journal of Behavioral Sciences, 9, 397-412.

Sheldon, K., Ryan, R., \& Reis, H. (1996). What makes for a good day? Competence and autonomy in the day and in the person. Personality and Social Psychology Bulletin, 22, 1270-1279.

Soenens, B., Vansteenkiste, M., Lens, W., Luyckx, K., Goossens, L., Beyers, W., \& Ryan, R. (2007). Conceptualizing parental autonomy support: Adolescent perceptions of promotion of independence versus promotion of volitional functioning. Developmental Psychology, 43(3), 633-646. 
Soenens, B., \& Vansteenkiste, M. (2005). Antecedents and outcomes of self-determination in three life domains: The role of parents' and teachers' autonomy support. Journal of Youthand Adolescence, 34(6), 589-601.

Steinberg, L, Dornbusch, S., \& Brown, B. (1992). Ethnic differences in adolescent achievement: An ecological perspective. American Psychologist, 47, 723-729.

Sy, S. R. \& Schulenberg, J. E. (2005). Parent beliefs and children's achievement trajectories during the transition to school in Asian American and European American families. International Journal of Behavioral Development, 29(6), 505-515.

Vallerand, R., Pelletier, L., \& Blais, M. (1992) The Academic Motivation Scale: A measure of intrinsic, extrinsic, and amotivation in education. Educational and Psychological Measurement, 52(4), 1003-1017.

Vansteenkiste, M., Lens, W., De Witte, S., De Witte, H., \& Deci, E. (2004). The "why" and "why not" of job search behavior: Their relation to searching, unemployment experience, and well-being. European Journal of Social Psychology, 34, 345-363.

Vansteenkiste, M., Zhou, M., Lens, W., \& Soenens, B. (2005). Experiences of autonomy and control among Chinese learners: Vitalizing or immobilizing? Journal of Educational Psychology, 97(3), 468-483.

Yamauchi, H. \& Tanaka, K. (1998). Relations of autonomy, self-referenced beliefs and self regulated learning among Japanese children. Psychological reports, 82, 803-816. 